\title{
Produção de muda orgânica de pimentão com diferentes substratos
}

\author{
Organic production of seedlings of sweet pepper with different substrates
}

\section{Sebastião Elviro de Araújo Neto ${ }^{I}$ José Marlo Araújo de AzevedoII Robson de Oliveira GalvãoII Elizângela Barbosa de Lima Oliveira ${ }^{\text {II }}$ Regina Lúcia Félix Ferreira ${ }^{\text {II }}$}

\section{RESUMO}

A fase de muda na horticultura é fundamental para obter boa produtividade, e o substrato é grande responsável por isso. Objetivou-se, no presente trabalho, identificarem-se combinações de resíduos orgânicos na confecção de substratos para a produção de mudas de pimentão Casca Dura Avelar. Sementes foram semeadas em copos plásticos de $180 \mathrm{~cm}^{3}$, contendo misturas de resíduos orgânicos em cada substrato, como segue $T_{1}$ Plantmax ${ }^{\circledR}$ (tratamento controle); $T_{2}$ composto orgânico + casca de coco triturada $(1: 1 \mathrm{v} / \mathrm{v}) ; T_{3}$ composto orgânico + cama-de-frango + casca de arroz carbonizada (1:1:1 v/v); $T_{4}$ composto orgânico + esterco bovino + casca de arroz carbonizada $(1: 1: 1 \mathrm{v} / \mathrm{v}) ; T_{5}$ composto orgânico + coprólitos de minhoca + casca de arroz carbonizada $(1: 1: 1 \mathrm{v} / \mathrm{v}) ; T_{6}$ composto orgânico + caroço de açaí triturado $(1: 1: 1 \mathrm{v} / \mathrm{v}) ; T_{7}$ composto orgânico + coprólitos de minhoca + casca de coco triturada $(1: 1: 1 \mathrm{v} / \mathrm{v}) ; T_{8}$ composto orgânico + esterco bovino + casca de coco triturada (1:1:1 v/ v). Após a semeadura, os recipientes foram transferidos para casa de vegetação. O delineamento experimental utilizado foi o inteiramente casualizado, com oito tratamentos e quatro repetições, e a unidade experimental foi constituida de três plantas: uma em cada recipiente. Decorridos 20 dias da semeadura, avaliaram-se a altura de plantas, massa seca da parte aérea, massa seca de raízes e massa seca total. O substrato Plantmax $^{\circledast}$ foi o que apresentou melhor desempenho. Entre os substratos alternativos, o substrato $T 5$ foi o de melhor resultado.

Palavras-chave: Capsicum annuum, adubação orgânica, propagação.

\section{ABSTRACT}

The seedling's stage in the horticulture is fundamental to obtain good yield, and the substrate is the largest responsible for that. The objective of this research was to identify combination of organic residues in the confection of substrates for production of sweet pipper seedlings cv. Casca Dura Avelar. Seeds were sowed in plastic glasses of $180 \mathrm{~cm}^{3}$, containing mixtures of organic residues in each substrate, as it follows: T1 Plantimax ${ }^{\circledR}$ (treatment control), $T_{2}$ compost organic + coconut peel $(1: 1 \mathrm{v} / \mathrm{v}), T_{3}$ compost organic + bed-of-chicken + peel-of-rice carbonized (1:1:1 v/v), $T_{4}$ compost organic + manure bovine + peel-of-rice carbonized (1:1:1 v/v), $T_{5}$ compost organic + earthworm casting + peel-of-rice carbonized (1:1:1 $v / v), T_{6}$ compost organic + earthworm casting + pit of triturated açaí $(1: 1: 1 \mathrm{v} / \mathrm{v}), T_{7}$ compost organic + earthworm casting + peel of triturated coconut $(1: 1: 1 \mathrm{v} / \mathrm{v}), T_{8}$ compost organic + manure bovine + peel of triturated coconut $(1: 1: 1 \mathrm{v} / \mathrm{v})$. The experiment followed a completely randomized design with eigth treatments and four replicates and three plants per plot. There was effect of the substrate in the production of seedlings of sweet pepper for all the analyzed characteristics. The substrate Plantmax ${ }^{\circledast}$ was what presented better acting. Among the alternative substrates, the $T_{5}$ was what presented the best result.

Key words: Capsicum annuum, organic manuring, propagation.

\section{INTRODUÇÃO}

O pimentão, Capsicum annuum (Solanaceae), é uma hortaliça de grande importância socioeconômica no Brasil, sendo comercializado como fruto verde, vermelho, amarelo, laranja, creme e roxo. Seu valor nutritivo, para consumo ao natural, deve-se, em grande parte, à presença de vitaminas, especialmente a vitamina C (CNPH, 2001).

Uma das principais etapas do sistema produtivo do pimentão é a produção de mudas de

ICentro de Ciências Naturais e da Terra, Universidade Federal do Acre (UFAC), 69915-900, Campus Universitário, BR 364, km04, Distrito Industrial, Rio Branco, Acre, Brasil. E-mail: selviro2000@yahoo.com.br. Autor para correspondência.

IIMestrado em Produção Vegetal (UFAC), Rio Branco, AC, Brasil. 
qualidade, pois delas depende o desempenho final das plantas no campo de produção (ANDRIOLO, 2000). A utilização de recipientes com substratos em substituição ao uso de solo, na formação de mudas, tem proporcionado melhorias substanciais na qualidade destas (SMIDERLE et al., 2001; RAMOS et al., 2002), sendo os substratos comerciais considerados de melhor qualidade, podendo o viveirista e/ou o horticultor desenvolverem seu próprio substrato com menor custo e utilizando material mais próximo da propriedade.

Um substrato influi, por meio de sua fase sólida, na manutenção do sistema radicular da planta; no suprimento de água e nutrientes pela fase líquida; no oxigênio e transporte de carbono entre as raízes; e no ar externo pela fase gasosa (MINAMI \& PUCHALA, 2000). Assim, além das propriedades químicas e físicohídricas adequadas, para melhorarem a relação água/ar e a disponibilidade de nutrientes (FERNANDES \& CORÁ, 2000), os substratos devem estar livres de fitopatógenos e sementes de plantas indesejáveis, bem como serem compostos por materiais de baixo custo, fácil aquisição (FACHINELLO et al., 2005), longa durabilidade e recicláveis, ou ainda desenvolverem métodos para reaproveitamento e melhoria das condições químicas e físicas do solo (SASSAKI, 1997).

Entretanto, é praticamente impossível encontrar um substrato com todas as características citadas, daí a necessidade de se misturarem vários materiais para se conseguir um substrato próximo ao ideal. De acordo com SOUZA (1993), a casca de arroz carbonizada pode ser utilizada como substrato alternativo por apresentar boa penetração e troca de ar na base das raízes, ser leve e porosa, permitindo boa aeração e drenagem, ser firme e densa para fixar a muda, apresentar volume constante, seca ou úmida; isenção de plantas daninhas e patógenos, além de não necessitar de tratamento químico para esterilização.

O carvão triturado ou fino de carvão extraído no processo de tamização, na classificação do carvão vegetal, apresenta uma estrutura altamente porosa que, ao ser misturado ao solo ou substrato, aumenta a porosidade, capacidade de retenção de água e facilita a disseminação de microorganismos benéficos (ZANETTI et al., 2003). A casca de coco verde é um subproduto do coco, sendo um material de difícil decomposição por possuir alta relação $\mathrm{C} / \mathrm{N}$ e sua utilização apresenta importância econômica e socioambiental (CARRIJO et al., 2002). Além disso, reduz o custo da produção de mudas em até $47 \%$, como ocorre nas mudas de tomate (SILVEIRA et al., 2002). O caroço de açaí triturado, um subproduto do beneficiamento do fruto do açaizeiro, é abundante na
Amazônia e recomendado como adubo para cultivo de hortaliças e plantas ornamentais (ROGEZ, 2000; GONÇALVES et al., 2006). O uso de coprólitos ou húmus de minhoca, por serem ricos em fósforo, cálcio e potássio, podem fazer parte da composição de substratos para produção de mudas orgânicas. Em couve-manteiga, SILVA et al. (2007) observaram que o benefício desse substrato é maior, quando a sua condição química é superior à do solo em fornecer nutrientes para as plantas.

Portanto, o aproveitamento dos resíduos orgânicos disponíveis nas propriedades rurais, para produção de mudas, constitui-se numa fonte de nutrientes economicamente importante, por reduzir os custos decorrentes da aquisição de adubos químicos para esse fim, principalmente, se for considerada a posição geográfica do Estado do Acre em relação aos grandes centros, o que, devido ao transporte, aumenta os custos dos insumos agrícolas.

Objetivou-se, no presente trabalho, identificar as combinações de resíduos orgânicos na confecção de substratos para a produção de mudas de pimentão Casca Dura Avelar.

\section{MATERIAL E MÉTODOS}

O experimento foi conduzido no campus da Universidade Federal do Acre, no período 01 a 20 de março de 2007. A cultivar foi a 'Casca Dura Avelar'. Foram utilizadas três sementes em cada copo plástico de $180 \mathrm{~cm}^{3}$, perfurados, na lateral e no fundo, para drenagem da água. Após a emergência, foi deixada apenas uma planta por recipiente, com aproximadamente de $4 \mathrm{~cm}$ de altura, com dois a quatro pares de folhas, descartando aquelas com defeitos e fora do padrão predeterminado.

Os substratos avaliados foram: $\mathrm{T}_{1}=$ Plantmax $^{\circledR}$ (tratamento controle); $\mathrm{T}_{2}=$ composto orgânico + casca de coco triturada $(1: 1 \mathrm{v} / \mathrm{v}) ; \mathrm{T}_{3}=$ composto orgânico + cama-de-frango + casca de arroz carbonizada $(1: 1: 1 \mathrm{v} / \mathrm{v}) ; \mathrm{T}_{4}=$ composto orgânico + esterco bovino + casca de arroz carbonizada (1:1:1 v/ v); $T_{5}=$ composto orgânico + coprólitos de minhoca + casca de arroz carbonizada $(1: 1: 1 \mathrm{v} / \mathrm{v}) ; \mathrm{T}_{6}=$ composto orgânico + caroço de açaí triturado $(1: 1: 1 \mathrm{v} / \mathrm{v}) ; \mathrm{T}_{7}=$ composto orgânico + coprólitos de minhoca + casca de coco triturada (1:1:1 v/v); $\mathrm{T}_{8}=$ composto orgânico + esterco bovino + casca de coco triturada (1:1:1 v/v). Foram adicionados aos tratamentos $10 \%$ de carvão vegetal triturado, $1,0 \mathrm{~kg} \mathrm{~m}^{-3}$ calcário e $1,5 \mathrm{~kg} \mathrm{~m}^{-3}$ de termofosfato, exceto no tratamento T1.

As análises químico-físicas dos substratos foram feitas no Instituto Campineiro de Análise de Solo e Água - ICASA (Tabelas 1 e 2 e Figura 1). As

Ciência Rural, v.39, n.5, ago, 2009. 
Tabela 1 - Composição química dos substratos.

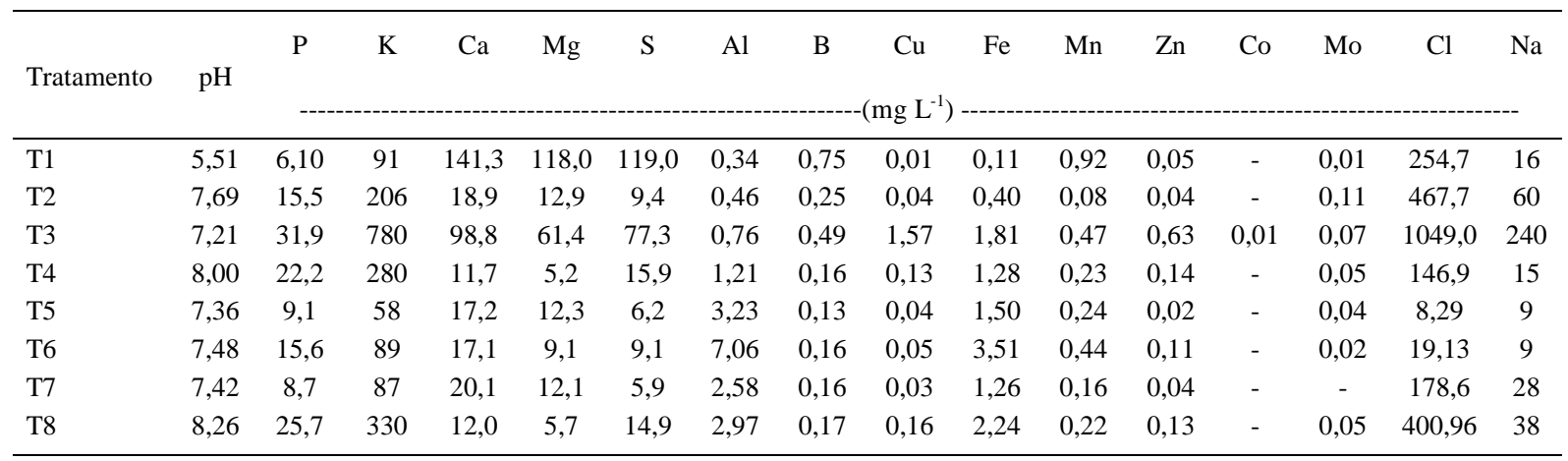

$\mathrm{T}_{1}$ Plantmax ${ }^{\circledR}$ (tratamento controle); $\mathrm{T}_{2}$ composto orgânico + casca de coco triturada; $\mathrm{T}_{3}$ composto orgânico + cama-de-frango + casca de arroz carbonizada; $T_{4}$ composto orgânico + esterco bovino + casca de arroz carbonizada; $T_{5}$ composto orgânico + coprólitos de minhoca + casca de arroz carbonizada; $\mathrm{T}_{6}$ composto orgânico + caroço de açaí triturado; $\mathrm{T}_{7}$ composto orgânico + coprólitos de minhoca + casca de coco triturada; $T_{8}$ composto orgânico + esterco bovino + casca de coco triturada.

densidades, úmida e seca, foram analisadas pelo método de Hoffmann, descrito por GROLLI (1991). As características de espaço poroso (PS), espaço de aeração (EA), água disponível (AD) e água remanescente a $100 \mathrm{~cm}(\mathrm{AR}-100)$ foram obtidas mediante curvas de retenção de água nas sucções de 0,10 e 100hPa (DE BOOT \& VERDONCK, 1972). Ovalor do $\mathrm{pH}$ foi determinado por meio de leituras feitas em suspensão de substrato em água, na proporção de 1:2,5 (v/v), mediante o uso de potenciômetro (HOFFMANN, 1970). Para a determinação da salinidade, utilizou-se o método proposto pela VDLUFA (ROBER \& SCHALLER, 1985).

As características avaliadas foram as seguintes: a)altura de planta (cm); b) massa seca da parte aérea (g), c) massa seca de raiz (g) e d) massa seca total (g). Aos 20 dias, após a semeadura, as características avaliadas foram: a)altura de planta $(\mathrm{cm})$; b) massa seca da parte aérea (g), c) massa seca de raízes (g) e d) massa seca total (g). A altura das mudas foi avaliada, com a utilização de trena graduada em centímetros e com medição do colo ao ápice da muda. O sistema radicular e a parte aérea foram secos em estufa com circulação forçada a $60^{\circ} \mathrm{C}$ por 72 horas. Os valores da massa fresca e da massa seca foram determinados com auxílio de balança analítica. A massa seca total resultou da soma da massa seca da parte aérea com a das raízes.

O delineamento experimental utilizado foi o inteiramente casualizado com oito tratamentos e quatro repetições, sendo que cada unidade experimental foi constituída de três plantas, uma em cada recipiente. Os dados foram submetidos à análise de variância e as médias agrupadas pelo teste de Scott Knott, a 5\% de probabilidade de erro, utilizando-se o programa SISVAR.

Tabela 2 - Características físicas dos substratos.

\begin{tabular}{|c|c|c|c|c|c|c|c|c|c|}
\hline \multirow[t]{2}{*}{ TRAT } & $\begin{array}{c}\mathrm{Da} \\
\text { (base seca) }\end{array}$ & $\begin{array}{c}\mathrm{Da} \\
\text { (base úmida) }\end{array}$ & Dp & PS & $\begin{array}{c}\text { Partículas } \\
\text { Sólidas }\end{array}$ & \multirow{2}{*}{$\begin{array}{c}\text { C.T.C. } \\
\left(\mathrm{mMol} \mathrm{cm}^{-3}\right)\end{array}$} & \multirow{2}{*}{$\begin{array}{l}\text { C.R.A. } \\
\left(\mathrm{m}^{3} \mathrm{~m}^{-3}\right)\end{array}$} & \multirow{2}{*}{$\begin{array}{c}\text { C.E. } \\
\left(\mathrm{dS} \mathrm{m}{ }^{-1}\right)\end{array}$} & \multirow{2}{*}{$\begin{array}{c}\text { M.O. } \\
\text { (g } 100 g^{-1} \text { ) }\end{array}$} \\
\hline & --------- & $-\left(\mathrm{kg} \mathrm{m}^{-3}\right)$ & -------- & ------ & v/v)-------- & & & & \\
\hline $\mathrm{T} 1$ & 503,8 & 427,07 & 1767,4 & 57,8 & 24,2 & 795,0 & 0,70 & 1,656 & 70,37 \\
\hline $\mathrm{T} 2$ & 237,8 & 210,98 & 1894,6 & 88,9 & 11,1 & 560,0 & 0,52 & 0,797 & 56,18 \\
\hline T3 & 367,4 & 334,53 & 1857,7 & 82,0 & 18,0 & 690,0 & 0,54 & 3,050 & 60,10 \\
\hline $\mathrm{T} 4$ & 493,2 & 439,28 & 2015,6 & 78,2 & 21,8 & 505,0 & 0,64 & 1,002 & 55,56 \\
\hline $\mathrm{T} 5$ & 804,5 & 756,48 & 2161,7 & 65,0 & 35,0 & 305,0 & 0,51 & 0,492 & 31,83 \\
\hline T6 & 788,0 & 734,78 & 2207,2 & 66,7 & 33,3 & 322,5 & 0,55 & 0,425 & 28,27 \\
\hline T7 & 529,6 & 511,33 & 2198,9 & 76,8 & 23,2 & 287,5 & 0,36 & 0,583 & 28,90 \\
\hline T8 & 301,8 & 276,18 & 2005,8 & 86,2 & 13,8 & 445,0 & 0,53 & 0,903 & 45,26 \\
\hline
\end{tabular}

Da = densidade aparente; $\mathrm{Dp}$ = densidade das partículas; PS = espaço poroso; C.T.C.= Capacidade de troca de cátions; C.R.A.= Capacidade de retenção de água; C.E. = condutividade elétrica; M.O. = matéria orgânica.

Ciência Rural, v.39, n.5, ago, 2009. 


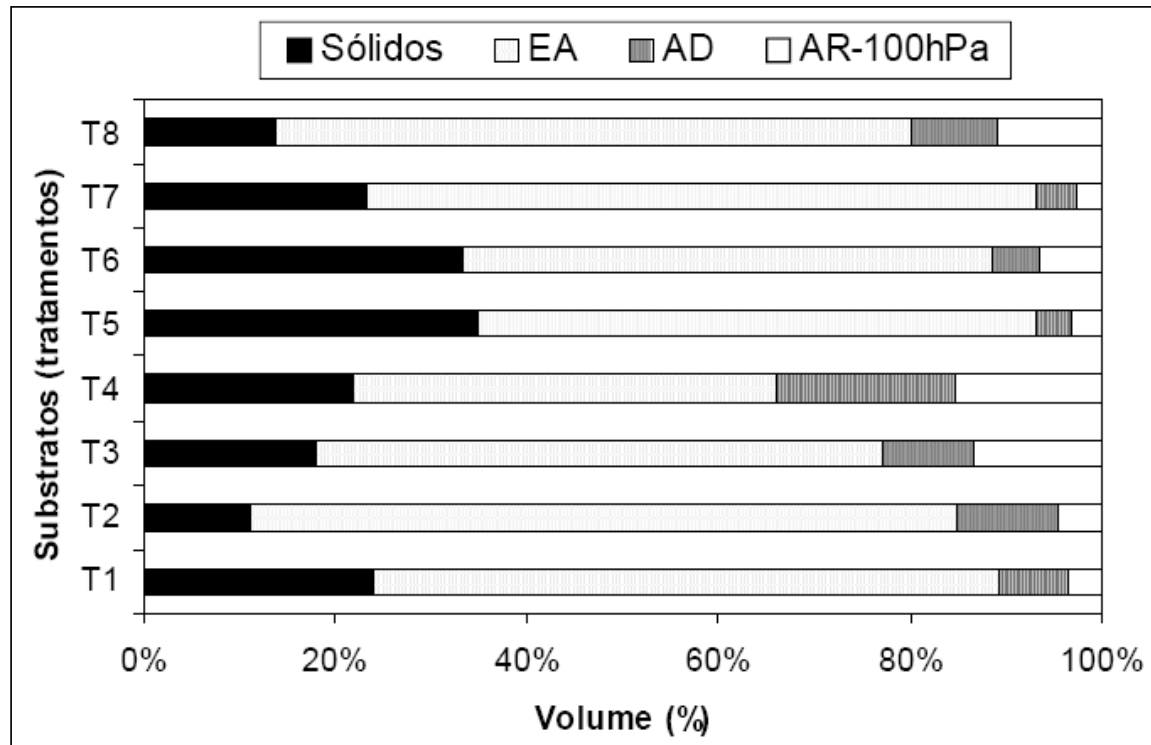

Figura 1 - Características físicas dos substratos analisados sob tensão de $50 \mathrm{~cm}$ de coluna de água. EA (espaço de aeração); AD (água disponível) AR-100 (Água remanescente a 100hPa).

\section{RESULTADOS E DISCUSSÃO}

Houve efeito dos substratos na produção de mudas de pimentão para todas as características analisadas (Tabela 3). O substrato comercial Plantmax ${ }^{\circledR}$ proporcionou maior altura das plantas, da massa seca da parte aérea, da massa seca de raiz e da massa seca total (Tabela 3). Esses efeitos são previsíveis, uma vez que esse substrato apresenta como características menor densidade e boa retenção de água, de acordo com a capacidade de campo, além de ser balanceado em sua composição química (MINAMI \& PUCHALA, 2000). Resultados similares com uso do Plantimax ${ }^{\circledR}$, na produção de mudas de pimentão, foram observados por LUZ et al. (2000) e SMIDERLE et al. (2001).

Dentre os substratos alternativos, aquele constituído de composto orgânico, coprólitos e cascade-arroz carbonizada $\left(T_{5}\right)$ foi o que apresentou o melhor resultado para as características massa seca de raiz e total, mas para a altura da planta e massa seca da parte aérea, a substituição do coprólito de minhocas do $\mathrm{T}_{5}$ pelo esterco bovino $\left(\mathrm{T}_{4}\right)$ contribuiu para não haver diferença significativa entre ambos (Tabela 3). Um dos fatores que contribuiu para isso foi a composição com casca de arroz carbonizado, presente nos substratos $\mathrm{T}_{4}$ e $\mathrm{T}_{5}$, a qual proporciona maior porosidade e aeração $\mathrm{e}$, consequentemente, maior capacidade de retenção de água (Figura 1). Além disso, o coprólito de minhoca e o esterco bovino, nos substratos $\mathrm{T}_{5}$ e $\mathrm{T}_{4}$, respectivamente, são componentes que promovem aumento do teor de M.O. e de nutrientes e, assim, complementam os efeitos físico-hídricos da casca-dearroz carbonizada. Além disso, ambos os tratamentos apresentaram bons teores de P e K (Tabela1), contribuindo com isso para um bom desenvolvimento das mudas.

Os tratamentos $\mathrm{T}_{2}, \mathrm{~T}_{3}, \mathrm{~T}_{6}, \mathrm{~T}_{7}$ e $\mathrm{T}_{8}$ foram inferiores ao $\mathrm{T}_{1}, \mathrm{~T}_{4}$ e $\mathrm{T}_{5}$, mas não diferiram estatisticamente entre si, para as variáveis: altura de planta, massa seca da parte aérea e de raizes, proporcionando menor desempenho no desenvolvimento das mudas (Tabela 3). A característica comum entre esses substratos é a substituição da cascade-arroz carbonizada, por casca-de-coco e caroço-deaçaí triturados, exceto no tratamento 3 . Os substratos, contendo casca-de-coco em sua composição, apresentam salinidade de média a alta, relação $\mathrm{C} / \mathrm{N}$ alta e condutividade elétrica alta. A baixa densidade dos referidos substratos é uma característica desfavorável (Figura 1), que pode causar baixa aderência às raízes, interferindo na absorção de nutrientes.

Observou-se neste trabalho que todos os substratos apresentaram entre $44 \%$ a $74 \%$ de espaço de aeração (EA), com 65\% de EA para o substrato padrão (Plantimax $^{\circledR}$ ), bem acima dos 30\% considerados por KÄMPF (2000) como limite máximo para substratos.

O tratamento $T_{3}$, apesar de possuir boas características físicas (Tabela 2), não proporcionou um bom desempenho das plântulas, provavelmente devido aos elevados teores de K e P (Tabela 1), cinco a três vezes acima do ótimo (110 a $179 \mathrm{mg} \mathrm{L}^{-1}$ para K e 8 a $13 \mathrm{mg} \mathrm{L}^{-1}$ para P), recomendado por PLANK (1989). Esse 
Tabela 3 - Altura de planta, Matéria seca da parte aérea (MSPA), Matéria seca de raizes (MSR) e matéria seca total (MST).

\begin{tabular}{|c|c|c|c|c|}
\hline \multirow{2}{*}{ Substratos } & \multirow{2}{*}{$\begin{array}{l}\text { Altura } \\
\text { (cm) }\end{array}$} & MSPA & MSR & MST \\
\hline & & \multicolumn{3}{|c|}{ 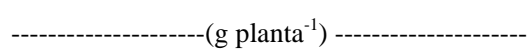 } \\
\hline T1 - Plantmax ${ }^{\circledR}$ (testemunha) & $11,0 a^{*}$ & $0,248 \mathrm{a}$ & $0,092 \mathrm{a}$ & $0,340 \mathrm{a}$ \\
\hline T2 - Composto orgânico (CO) + casca de coco & $4,7 \mathrm{c}$ & $0,021 \mathrm{c}$ & $0,012 \mathrm{c}$ & $0,033 \mathrm{~d}$ \\
\hline T3-CO+cama de aviário+casca-de-arroz carbonizada & $5,5 \mathrm{c}$ & 0,020 c & $0,008 \mathrm{c}$ & $0,028 \mathrm{~d}$ \\
\hline T4- CO+esterco bovino+casca-de-arroz carbonizada & $8,1 \mathrm{~b}$ & $0,082 \mathrm{~b}$ & $0,023 \mathrm{c}$ & $0,105 \mathrm{c}$ \\
\hline T5- CO + coprólito + casca-de-arroz carbonizada & $8,5 \mathrm{~b}$ & $0,104 \mathrm{~b}$ & $0,045 \mathrm{~b}$ & $0,149 \mathrm{~b}$ \\
\hline T6- CO + coprólito + caroço de açaí triturado & $3,1 \mathrm{c}$ & 0,012 c & $0,006 \mathrm{c}$ & $0,018 \mathrm{~d}$ \\
\hline T7- CO + coprólito + casca de coco triturado & $3,7 \mathrm{c}$ & 0,009 c & $0,004 \mathrm{c}$ & $0,013 \mathrm{~d}$ \\
\hline T8- CO + esterco bovino + casca de coco triturado & $4,3 \mathrm{c}$ & 0,013 с & $0,009 \mathrm{c}$ & $0,021 \mathrm{~d}$ \\
\hline Média & 6,1 & 0,064 & 0,025 & 0,088 \\
\hline CV (\%) & 15,91 & 15,50 & 31,02 & 16,10 \\
\hline
\end{tabular}

* Médias seguidas de letras distintas na coluna diferem entre si pelo teste de Scott Knott, a 5\% de probabilidade de erro.

substrato foi o que apresentou os maiores valores de $\mathrm{Cl}^{+}, \mathrm{Na}^{+}$(toxidez) e C.E. (3,05dS m $\left.{ }^{-1}\right)$. O valor de CE obtido é limitante para o crescimento da maioria das plantas, uma vez que deveria situar-se abaixo de $1 \mathrm{dS}$ $\mathrm{m}^{-1}$ para culturas sensíveis à salinidade (AYERS \& WESTCOT, 1991). Esse fato é devido provavelmente ao uso de cama-de-aviário pouco curtida, com elevados teores de nutrientes e sais $(\mathrm{K}, \mathrm{P}, \mathrm{Ca}, \mathrm{N}, \mathrm{Cl}$ e $\mathrm{Na}$ ) constituídos nos restos de ração depositados na cama.

Os valores de 2,0 a 4,0dS m $\mathrm{m}^{-1}$ de CE, para substratos, são considerados altos, pois de 1,0 a 2,0dS $\mathrm{m}^{-1}$ são normais e menor que $1,0 \mathrm{dS} \mathrm{m}^{-1}$ são considerados baixos KÄMPF (2000). Portanto, apenas $\left(T_{1}\right)$ e $\left(T_{4}\right)$ apresentaram concentrações normais de salinidade, já o $\left(\mathrm{T}_{3}\right)$ apresentou concentração alta e os demais concentrações baixas (Tabela 2).

A presença de $\mathrm{Na}^{+}$e $\mathrm{Cl}^{-}$no substrato tem proporcionado diminuição no crescimento dos vegetais, em virtude desses íons provocarem mudanças na capacidade das plantas em absorverem, transportarem e utilizarem algum nutriente essencial. Provavelmente, isso contribuiu para o baixo desempenho dos substratos $\mathrm{T}_{2}, \mathrm{~T}_{3}$ e $\mathrm{T}_{8}$ (Tabela 1 ).

$\mathrm{O}$ substrato $(\mathrm{T})$ apresentou os maiores valores de $\mathrm{Al}^{+}$(Quadro 1 ). ${ }^{6} \mathrm{O} \mathrm{Al}^{+}$afeta o crescimento das plantas e age nas regiões meristemáticas da raiz, causando a diminuição da absorção de água e nutrientes (FORTUNATO \& NICOLOSO, 2004) e a redução na concentração de $\mathrm{Ca}^{+2} \mathrm{e} \mathrm{Mg}^{+2}$, que inibe o crescimento vegetal e diminui a disponibilidade do $\mathrm{P}$ (SOARES et al., 2007). Além disso, seus mecanismos de ação fitotóxica interferem na divisão e expansão celular, causam desorganização da membrana plasmática e inibem a absorção de íons (SCHLINDWEIN et al., 2003).
Para as características físicas dos substratos, verificou-se que a capacidade de retenção de água (CRA) variou de 0,36 a $0,70 \mathrm{~m}^{3} \mathrm{~m}^{-3}$ (Tabela 2), valores inferiores ao recomendado por FERRAZ et al. (2005) para substratos $\left(0,75 \mathrm{~m}^{3} \mathrm{~m}^{-3}-0,90 \mathrm{~m}^{3} \mathrm{~m}^{-3}\right)$. Os autores citam ainda que esses valores são maiores para substratos, quando comparados a solos, em virtude da maior quantidade de água utilizada no cultivo das plantas em substratos.

No que se refere à água disponível (AD), todos o substratos apresentaram valores que variaram de $0,38 \mathrm{~m}^{3} \mathrm{~m}^{-3}$ no tratamento $\left(\mathrm{T}_{5}\right)$ a $0,19 \mathrm{~m}^{3} \mathrm{~m}^{-3}$ no $\left(\mathrm{T}_{4}\right)$ (Figura 1). Valores esses que ficaram dentro da margem sugerida por FERRAZ et al. (2005) que é de $0,20 \mathrm{~m}^{3} \mathrm{~m}^{-3}$ a $0,40 \mathrm{~m}^{3} \mathrm{~m}^{-3}$. Os substratos $\left(T_{5}\right),\left(T_{6}\right)$ e $\left(T_{7}\right)$ apresentaram baixa quantidade de água disponível (AD) (Tabela 2), o que provavelmente ocorreu em função da presença de coprólitos de minhoca terem promovido um adensamento no substrato e diminuído a quantidade de água disponível.

\section{CONCLUSÃO}

O substrato contendo esterco bovino ou coprólitos de minhoca, como fonte de nutrientes, e a casca de arroz carbonizada, como condicionante físico, podem ser utilizados na composição de substratos alternativos para à produção de mudas de pimentão, enquanto os substratos à base de cama-de-frango e caroço-de-açaí ou casca-de-coco não são indicados para composição de substratos para pimentão.

\section{REFERÊNCIAS}

ANDRIOLO, J.L. Fisiologia da produção de hortaliças em ambiente protegido. Horticultura Brasileira, Brasília, v.18, supl, p.26-32, 2000.

Ciência Rural, v.39, n.5, ago, 2009. 
AYERS, R.S.; WESTCOT, D.W. A qualidade da água de irrigação na agricultura. Campina Grande: UFPB, 1991. 218p. (FAO. Estudos de Irrigação e Drenagem, 29; revisado 1).

CARRIJO, O.A. et al. Fibra da casca de coco verde como substrato agrícola. Horticultura Brasileira, Brasília, v.20, n.4, p.533-535, 2002. Disponível em: <http://www.scielo.br/ scielo.php? script =sci_arttext \& pid=S0102 05362002000400003\&lng=pt\&nrm=iso>. Doi: 10.1590/ S0102-05362002000400003.

CNPH. Projeto Capsicum. Embrapa Hortaliças. 2001. Acessado em :10/12/2008. Online. Disponível em : http:// www.cnph.embrapa.br/projetos/capsicum/index.html.

DE BOODT, M.; VERDONCK, O. The physical properties of the substrates in floriculture. Acta Horticulture, Wageningen, v.26, p.37-44, 1972

FACHINELLO, J.C. et. al. Propagação de plantas frutíferas. Brasília: Embrapa Informação Tecnológica, 2005. 221p.

FERNANDES, C.; CORÁ, J.E. Caracterização físico-hídrica de substratos utilizados no cultivo de hortaliças Horticultura Brasileira, Brasília, v.18, Supl jul, p.471-473, 2000.

FERRAZ, M.V. et. al. Caracterização física e química de alguns substratos comerciais. Acta Scientiarum Agronomy, Maringá, v.27, n.2, p.209-214, 2005.

FORTUNATO, R.P.; NICOLOSO, F.T. Toxidez de alumínio em plântulas de Grápia (Apuleia leiocarpa Vog. Macbride). Ciência Rural, Santa Maria, v.34, n.89-95, 2004

GONÇALVES, A.C.S. et. al. Pesquisas realizadas sobre o caroço de açaí. Acesso em: 23 nov. 2006. Online. Disponível em: http://www2.uepa.br/tecnagro/Pesqcarocoacai.htm

GROLLI, P.R. Composto de lixo domiciliar urbano como condicionador de substratos para plantas arbóreas. 1991. 125f. Dissertação (Mestrado em Fitotecnia) - Faculdade de Agronomia, UFRGS, Porto Alegre, RS.

HOFFMANN, G. Verbindliche methoden zur undersuchung von TKS und gartnerischen erden. Mitteilungen der VDLUFA Heft, v.6, p.129-153, 1970.

LUZ, J.M.Q. et al. Produção de mudas de alface, tomateiro e couve-flor em diferentes substratos comerciais. Horticultura Brasileira, v.18, supl, p.579-581, 2000.

De BOOT, M.; HAYNES, R.J. The physical proprieties of the substrates in horticulture. Acta Horticulturae, Wagerningen, n.26, p.37-44, 1972.

KÄMPF, A.N. Seleção de materiais para uso como substrato. In KÄMPF, A.N.; FIRMINO, M.H. (Eds). Substrato para plantas: a base da produção vegetal em recipientes. Porto Alegre: Gênesis, 2000. p.139-145.
MINAMI, K.; PUCHALA, B. Produção de mudas de hortaliças de alta qualidade. Horticultura Brasileira, Brasília, v.18, supl, p.162-163, 2000.

PLANK, C.O. Soil test handbook for Georgia. Athens: University of Georgia, 1989. 316p.

RAMOS, J.D. et al. Produção de mudas de plantas frutíferas por semente. Informe Agropecuário, Belo Horizonte, v.23, p.6472, 2002.

ROBER, R.; SCHALLER, K. Pflanzenernahrung im Gartenbau. Stuttgart: Ulmer, 1985. 352p.

ROGEZ, H. Açaí: preparo, composição e melhoramento da conservação. Belém: EDUFPA, 2000. 313p.

SASSAKI, O.K. Resultados preliminares da produção de hortaliças sem o uso de solo no Amazonas. Horticultura Brasileira, Brasília, v.15, p.165-169, 1997.

SCHLINDWEIN, J.A. et al. Redução da toxidez de alumínio em raízes de soja por culturas antecessoras no sistema plantio direto. Revista Brasileira de Agrociência, Pelotas, v.9, n.1, p.85-88, 2003.

SILVA, S.S. da. et al. Produção orgânica de mudas de couvemanteiga em substratos à base de coprolito de minhocas. Caatinga, Mossoró, v.20, n.4, p.78-83, 2007.

SILVEIRA, E.B. et al. Pó de coco para substrato de mudas de tomateiro. Horticultura Brasileira, Brasília, v.20, n.2, p.211216, 2002. Disponível em: <http://www.scielo.br/ scielo.php ? script=sci_arttext \& pid=S 0102 05362002000200019\&lng $=$ pt $\&$ nrm=iso $>$. Doi: 10.1590/ S0102-05362002000200019>.

SMIDERLE O.J. et al. Produção de mudas de alface, pepino e pimentão em substratos combinando areia, solo e Plantmax ${ }^{\circledR}$. Horticultura Brasileira, Brasília, v.19, n.3, p.253-257, 2001. Disponível em: $<$ http://www.scielo.br/scielo.php?script=sci_arttext\&pid=S010205362001000300022\&lng=pt\&nrm=iso >. Doi: $10.1590 /$ S010205362001000300022>

SOARES, A.R. et. al. Identificação de tolerância à toxidez por alumínio em genótipos de Brachiaria sp. Acesso em 21/01/2007. Online. Disponível em: <https://sec.sbq.org.br/ cd29/resumos/T0822-1.pdf $>$.

SOUZA, F.X. de. Casca de arroz carbonizada: um substrato para a propagação de plantas. CNPAI/EMBRAPA. Revista Lavoura Arrozeira, Porto Alegre, v.46, n.406, p.11, 1993.

ZANETTI, M. et al. Uso de subprodutos de carvão vegetal na formação de porta enxerto limoeiro "Cravo" em ambiente protegido. Revista Brasileira de Fruticultura, Jaboticabal, v.25, n.3, p.508-512, 2003 . Disponível em: <http:// www.scielo.br/scielo.php?script=sci_arttext\&pid=S010029452003000300037\&lng=pt\&nrm=iso $>$. Doi: 10.1590/ S0100-29452003000300037. 